\title{
Particularities of Tuberculosis in Children and Adolescents with Sickle Cell Disease in Senegal
}

\author{
Idrissa Demba Ba*, Indou Deme/Ly, Yaye Joor Dieng, Abou Ba, Babacar Niang, \\ Aliou Abdoulaye Ndongo, Papa Moctar Faye, Guillaye Diagne, Amadou Sow, Fatima Tall/Fall, \\ Amadou Lamine Fall, Ousmane Ndiaye
}

Hôpital d'enfants Albert-Royer de Fann-Dakar, Université Cheikh Anta Diop de Dakar, Fann, Dakar, Senegal

Email: *docteuridy@hotmail.com

How to cite this paper: Ba, I.D., Deme/Ly, I., Dieng, Y.J., Ba, A., Niang, B., Ndongo, A.A., Faye, P.M., Diagne, G., Sow, A., Tall/ Fall, F., Fall, A.L. and Ndiaye, O. (2022) Particularities of Tuberculosis in Children and Adolescents with Sickle Cell Disease in Senegal. Open Journal of Pediatrics, 12, 5966.

https://doi.org/10.4236/ojped.2022.121007

Received: January 8, 2022

Accepted: February 12, 2022

Published: February 15, 2022

Copyright $\odot 2022$ by author(s) and Scientific Research Publishing Inc. This work is licensed under the Creative Commons Attribution International License (CC BY 4.0).

http://creativecommons.org/licenses/by/4.0/

\begin{abstract}
Introduction: Tuberculosis and sickle cell disease are one of the main global health priorities particularly in Africa. We aimed to determine the epidemiological, diagnostic and therapeutic aspects of tuberculosis in children and adolescents with sickle cell disease. Patients and methods: Patients aged 0 - 20 years with sickle cell anemia presented with tuberculosis at the Centre Hospitalier National d'Enfants Albert Royer (CHNEAR), Dakar, Senegal were included in the study. Medical history, risk factors, clinical, bacteriological, and outcome data was collected. Data was analyzed using the SPSS software, version 16. Results: A total of 25 cases of tuberculosis were documented from January $1^{\text {st }}, 1991$ to December 31 $1^{\text {st }}, 2019$ (hospital prevalence: 0.97\%). Mean age was 12.5 years. The sex ratio was 1.5 (15 girls and 10 boys). Pulmonary tuberculosis in 14 cases was the most frequent followed by lymph nodes in 7 cases involvement and Pott's disease in 4 cases. In 5 patients $\mathrm{Tb}$ was multifocal. Mean duration of treatment was 8.27 months (6 to 12 months). Outcome was good on antituberculosis treatment. None patient died. Conclusion: Children and adolescents with sickle cell disease can be infected with Mycobacterium tuberculosis. Pulmonary tuberculosis, lymph nodes and bone involvement are the most frequent localizations. Outcome is good on antituberculosis treatment.
\end{abstract}

\section{Keywords}

Tuberculosis, Sickle Cell Disease, Children, Adolescent, Senegal

\section{Introduction}

Tuberculosis remains a major public health problem responsible for significant morbidity and mortality worldwide. Tuberculosis is one of the top 10 causes of 
death worldwide. World Health Organization (WHO) estimated the number of new $\mathrm{Tb}$ cases at 10 million and the majority of cases occurred in developing countries [1]. HIV infection, malnutrition, children under 5 years old are main risk factors [2]. Tuberculosis and HIV infection form a morbid association responsible for millions of deaths in Africa [3]. Sickle cell disease, most common genetic disease in the world (500 million carriers worldwide, 300,000 children are born with this anomaly and 50 million affected individuals) is very frequent in Africa [4]. Sickle cell disease is also an important but largely neglected risk to child survival in most African countries [5]. In Senegal, the prevalence is about $10 \%$ in the general population and $2 \%$ of children are born with sickle cell disease major syndrome [6]. Patients with sickle cell disease have a high susceptibility to bacterial infections. The exact prevalence of tuberculosis in children and adolescent with sickle cell disease is unknowns. The aim of this study is to determine the epidemiological, diagnostic, therapeutic and evolutionary aspects of tuberculosis in children and adolescents with sickle cell disease in a pediatric hospital of Dakar.

\section{Material and Methods}

We conducted a descriptive, analytical, and retrospective study over a 19-years period (from January $1^{\text {st }}, 1991$ to December $31^{\text {st }}, 2019$ ) in the largest pediatric hospital of the country: the CHNEAR, Dakar, Senegal. This hospital is of the highest level for children our country with 170 beds and medical and surgical wards. Most children of the Dakar region presenting with severe diseases, or even patients from other regions, are managed at the CHNEAR. We focused on all children and adolescents aged 0 to 20 suffering from a major sickle cell syndrome (hemoglobin electrophoresis profile SS or SC or S-beta thalassemia) and presenting tuberculosis. Tuberculosis diagnosis was made based on one or more of the following criteria: a close contact tuberculosis infection, with the presence of symptoms suggestive of tuberculosis (chronic cough, deterioration in general condition, fever lasting more than 15 days, hemoptysis), a positive PPD, radiographic images suspicious of tuberculosis, the presence of acid fast bacilli (AFB) in the biological fluid or a positive Genexpert and one improvement under anti-tuberculosis treatment.

We did not include non-tuberculous infections, incomplete or lost records in the study.

We collected data from patient's medical records and follow-up registers. For each patient we studied socio-demographic data (age, sex, address, socio-economic level), medical history (age at diagnosis of sickle cell disease, clinical data, localization of tuberculosis), biology, bacteriology, imaging), treatment and outcome.

Data collected was entered and analysis using the CDC's Epi info 7 software.

\section{Result}

We identified 25 cases of tuberculosis cases among the sickle cell anemia child- 
ren and adolescent patients (hospital prevalence: 0.97\%). Hemoglobin electrophoresis profiles were SS in all patients. The socio-demographic characteristics of the children are described in Table 1. There female and girl ratio was 1.5 (15 girls, 10 boys). Mean age was 12.54 years. Thirteen (13) patients came from families with a low socio-economic level ( 15 children). The geographic origin of patients was suburban area in 12 cases and rural area in 3 cases.

Table 1. Epidemiological, clinical, bacteriological characteristics of children and adolescent suffering sickle cell disease and presenting tuberculosis.

\begin{tabular}{|c|c|c|}
\hline Characteristics & Patients (n) & Pourcentage (\%) \\
\hline \multicolumn{3}{|l|}{ Age groups } \\
\hline 0 - 5 years & 2 & 8 \\
\hline $5-10$ years & 7 & 28 \\
\hline $10-15$ years & 4 & 18 \\
\hline 15 - 19 years & 12 & 48 \\
\hline \multicolumn{3}{|l|}{ Sexe } \\
\hline Boys & 10 & 40 \\
\hline Girls & 15 & 60 \\
\hline \multicolumn{3}{|l|}{ Geographic origin } \\
\hline Suburban area & 12 & 48 \\
\hline City center & 10 & 40 \\
\hline Rural area & 3 & 12 \\
\hline \multicolumn{3}{|l|}{ Chest- $\mathrm{X}$ ray result } \\
\hline Normal & 17 & \\
\hline Abnormal & 8 & \\
\hline \multicolumn{3}{|l|}{ Clinical symptoms } \\
\hline Prolonged fever & 19 & 76 \\
\hline Chronic cough & 12 & 48 \\
\hline Chest pain & 11 & 44 \\
\hline Dorsolumbar pain & 5 & 20 \\
\hline Hemoptysis & 11 & 44 \\
\hline Weight loss & 5 & 20 \\
\hline \multicolumn{3}{|l|}{ Comorbidities } \\
\hline Malnutrition & 14 & 56 \\
\hline Asthma & 1 & 4 \\
\hline Congenital heart disease & 1 & 4 \\
\hline Tb complications & 1 & 4 \\
\hline Case fatality & 0 & 0 \\
\hline
\end{tabular}


All children had received a BCG vaccination at birth. Three (3) patient were close contact TB patient. The cases index was paternal uncle in 1 case, maternal uncle in 1 case and housekeeper in 1 case. Malnutrition was present in 14 children. Other comorbidities were asthma in 1 case and heart disease in 1 case.

Clinical symptoms was dominated by evening fever in 19 cases, chronic cough in 14 cases, chest pain in 13 cases, hemoptysis in 2 cases. Physical exam findings are listed in Table 1 . Chest x-ray performed for all patients showed abnormalities in 17 children: lung opacities in 10 cases, mediastinal adenopathy in 4 cases and pleural effusion in 1 case.

Spinal X-ray performed in 5 patients showed spondilodiscitis in 2 patients, vertebral narrowing with paravertebral abscess in 1 patient and narrowing of the vertebral disc in 1 patient. Abdominal ultrason found deep lymphadenopathy in 3 children. Magnetic Resonance Imaging (MRI) performed in 1 patient, she had objectified an aspect in favor of infarction of the vertebral bodies as well as the posterior arches.

Blood count found hyperleukocytosis in 15 cases and thrombocytosis in 2 cases. None leukopenia or thrombocytopenia was noticed. Anemia was present in all children with an average hemoglobin level of $7.42 \mathrm{~g} / \mathrm{dl}$. CRP was positive in 14 patients (mean CRP of $36.81 \mathrm{mg} / \mathrm{l}$ ). Renal function was normal in all children. PPD was positive in 20 patients.

Bacilloscopy performed in all children was positive in $16 \%$ (4 cases). Four (4) children benefited from a Genexpert test and 1 was postitive. Skin biopsy was performed in 2 children and showed a gigantocellular caseous granuloma in favor of tuberculosis. Lymph node biopsy was performed in a patient who showed the appearance of a tubercular granuloma.

Pulmonary $\mathrm{Tb}$ localization was predominant in 63\% (14 patients), followed by lymph node localization in $28 \%$ ( 7 cases) and Pott's disease in 1 case. Table 2 represented different $\mathrm{Tb}$ localizations.

Antituberculosis regimen was mainly RHZE 18 patiens, RHZ in 5 cases and Streptomycine (SRHZE) in 2 cases (Table 3 ). The anti-Tb treatment duration varied between 6 and 12 months depending on the site of the tuberculosis (average of 8.7 months). The patients all received folic acid in 25 cases and analgesics

Table 2. Different tuberculosis site noticed in sickle cell disease patients $(\mathrm{N}=25)$.

\begin{tabular}{ccc}
\hline Tuberculosis sites & Patients (n) & Pourcentage (\%) \\
\hline Pulmonary tuberculosis & 14 & 63 \\
Lymph node tuberculosis & 7 & 32 \\
Pott's disease & 4 & 18 \\
Skin tuberculosis & 2 & 9 \\
Multifocal tuberculosis* & 5 & 20 \\
Pleural tuberculosis & 2 & 9 \\
\hline
\end{tabular}

${ }^{\star}$ Five 5 patients presented with more than 1 localization. 
Table 3. Different anti-tuberculosis treatment regimen.

\begin{tabular}{ccc}
\hline Type of antituberculosis regimen & Number of cases (n) & Pourcentage (\%) \\
\hline RHZE $^{*}$ & 18 & 72 \\
RHZ $^{\star}$ & 5 & 20 \\
SRHZE $^{\star}$ & 2 & 8 \\
Total & 22 & 100 \\
\hline
\end{tabular}

${ }^{\star}$ RHZE: Rifampicine, Isoniazide, Pyrazinamide, Ethambutol; ${ }^{\star} \mathrm{RHZ}^{\star}$ : Rifampicine, $\mathrm{H}$ isoniazide, Z: Pyrazinamide; ${ }^{\star}$ SRHZE ${ }^{\star}$ R: Streptomycine, Rifampicine, Isoniazide, Pyrazinamide, Ethambutol.

(paracetamol and/or anti-inflammatory). Only 10 children benefited from blood transfusion, oxygen therapy in 4 cases and hydroxyurea in 2 cases.

Outcome was favorable in all the children. No child had died. We noticed 1 case of spinal cord compression. None had died in our series. Complications related to sickle cell disease were vaso-occlusive crisis in 12 cases, acute anemia in 5 cases, gallstones in 1 case, femoral head osteonecrosis of the femoral in 1 case and leg ulcer in 1 case.

\section{Discussion}

The incidence of tuberculosis in children and adolescents with sickle cell disease is $0.97 \%$ at the CHNEAR, Dakar, Senegal. In the literature, data are rare concerning the incidence of tuberculosis in children with sickle cell disease. In general studies concern adult population [7]. Koffi reported 4 cases of tuberculosis in children with sickle cell disease from 1993 to1998) at Ivory Coast [8]. Of the 2,580 children followed for major sickle cell disease from the 3 major pediatric centers in Paris, France, only 11 children had developed tuberculosis between 2000 and 2013 (Prevalence 0.42\%) [9].

We noticed despite the susceptibility of children with sickle cell disease to bacterial infections this incidence is similar to other children: $0.96 \%$ in children [2]. This is probably explained by the fact that CD4 lymphocytes are the support of immunity against Mycobacterium tuberculosis. In sickle cell disease, the immune deficiency is mainly linked to functional asplenia and lack of complement opsonization [10]. Thus children and adolescents with sickle cell disease are not more at risk of developing tuberculosis than other children in Senegal. Also in Africa, HIV infection remains the main determinant of tuberculosis in Africa. And Senegal is one of the countries with a very low incidence of HIV in Africa: $0.8 \%$ of prevalence [11].

The distribution of sickle cell disease varies from $10 \%$ to $40 \%$ depending on the regions and ethnic groups in Africa [12] [13]. In Senegal, $8 \%$ to $10 \%$ of the population carries hemoglobin $S$ gene and about $2 \%$ of newborns suffer from major forms of sickle cell disease [6].

Mean age of our patients is 12.5 years. Tuberculosis is more frequently diagnosed in older children and adolescents [8] [9]. 
The clinical signs of tuberculosis are very similar to those of adults and the bacteriological yield is higher in older children and adolescents [14].

Forty eight $48 \%$ of our patients came from Dakar suburban area proximity and high population density. These conditions are favorable for spread of transmission of tuberculosis in the neighborhood [2]. Three children (3) was close contact of $\mathrm{Tb}$ case. Intra-familial tuberculosis transmission is very common in pediatric population [15] [16] [17]. Tuberculosis infection should be suspected in children with close contact of $\mathrm{Tb}$. However, in limited countries resources case index's is not always confirmed because of the social nature of Tb and Families fear the stigma of the neighborhood.

Hemoglobin electrophoresis profile of our patients was homozygous SS form (100\%). This form represents the most severe and the most serious of the SCD. Lionnet in France had reported homozygous SS, heterozygous $S \beta+S \beta 0$ in his study [7]. The age of SCD in Senegal is often late (average age of 5.4 years in our study). This is related to the particularity of the Senegalese haplotype characterized by a high level of high fetal hemoglobin ( $\mathrm{HbF}$ ). A HbF level considerably attenuates the severity of the disease [18] [19]. HbF average was $13.17 \%$ in our study. Hence the need is to set up a neonatal screening program for SCD in low incoming countries with high incidence of this disease.

Prolonged fever in 19 cases, chronic cough in 12 cases, chest pain in 11 cases, back pain in 5 cases, weight loss in 5 cases were the clinical symptoms, and anorexia in 3 cases. Similar data have been reported by other authors [8] [7].

Main radiological abnormalities found in our patients were parenchymal opacities in 9 cases, mediastinal adenopathy in 2 cases, pleural effusion in 2 cases and thickening of the soft tissues in 4 cases. These abnormalities are usually noticed in in studies [20] [21]. In our series, pulmonary localization was more common in 14 cases, followed by lymph node involvement in 7 cases. Pott's disease in 4 cases, cutaneous localization in 2 cases and pleural involvement in 2 cases. Four patients presented with multifocal tuberculosis aged respectively 6, 8, 11 and 15 years. The bone involvement in SCD patients is probably due to the bone hypoperfusion. Lionnet reported Pott's disease in 2 cases [16]. Our results were similar in other studies [2] [8].

Acid fast bacilli (AFB) research is a very important for the Tb diagnosis. Sputum smears are positive in children in only $10 \%$ to $15 \%$, and culture in $30 \%$ to $40 \%$ of cases [22] [23]. In our series, the sputum smears were positive in $16 \%$ (4 cases). Culture is not carried out systematically. GeneXpert is a very useful test for $\mathrm{Tb}$ diagnosis in children and suspected multi-resistant tuberculosis cases. GeneXpert was introduced into our hospital in 2012. Only 4 children had benefited from Genexpert and 1 was positive.

Antituberculosis treatment protocols were RHZE in 18 cases, RHZ in 5 cases and SRHZE in 2 cases. These were consistent with the recommendations of Senegalese's national Tb control program. Outcome was good. None children died. 


\section{Conclusion}

Tuberculosis is a major public health problem responsible for significant morbidity and mortality in Senegal. Children and adolescents with sickle cell disease can be infected with Mycobacterium tuberculosis. Pulmonary tuberculosis, lymph nodes and bone involvement are the most frequent localizations. Outcome is good on antituberculosis treatment.

\section{Conflicts of Interest}

The authors declare no conflicts of interest regarding the publication of this paper.

\section{References}

[1] World Health Organization (2017) Global Tuberculosis: Control the Burden of Disease Caused by Tuberculosis. WHO, Geneva.

[2] Ba, I.D., Ba, A., Faye, P.M., Thiongane, A., Déme/Ly, I. and Ba, M. (2015) La tuberculose de l'enfant au Sénégal Aspects clinique, épidémiologiques, thérapeutiques et évolutifs. Médecine d' Afrique Noire, 62, 200-206.

[3] World Health Organization (2014) Co-Infection Tuberculose/VIH: WHO Report. WHO, Geneva.

[4] Modell, B. and Darlison, M. (2008) Global Epidemiology of Haemoglobin Disorders and Derived Service Indicators. Bulletin of the World Health Organization, 86, 480-487. https://doi.org/10.2471/BLT.06.036673

[5] Grosse, S.D., Odame, I., Hani, K., Atrash, H.K., Amendah, D.D., Piel, F.B. and Williams, T.N. (2011) Sickle Cell Disease in Africa. American Journal of Preventive Medicine, 41, S398-S405. https://doi.org/10.1016/j.amepre.2011.09.013

[6] Mbodj, M., Ndoye, O., Diarra, M., Mbaye, B.N., Sow Touré, H., Diouf, L., et al. (2003) Dépistage néonatal de la drépanocytose au CHU de Dakar: Premier bilan. Dakar Medical, 48, 202-205.

[7] Ahmed, S.G., Bukar, A.A. and Jolayemi, B. (2010) Hematological Indices of Sickle Cell Anemia Patients with Pulmonary. Tuberculosis in Northern Nigeria. Mediterranean Journal of Hematology and Infectious Diseases, 2, e2010014.

[8] M'Pemba, A.B., Youndouka, J.M., Pambou, B. and Nzingoula, S. (2008) La tuberculose chez l'enfant au CHU de Brazzaville. Bulletin de la Société de Pathologie EXotique, 101, 303-307.

[9] Droz, N., De Lausanne, A., Holvoet, L., Missud, F., Benkerrou, M., Brousse, V., Odievre, M.H., Faye, A. and Berengere, K.L. (2017) Tuberculosis in Children with Sickle Cell Anemia: A Retrospective Study in French Tertiary Care Centres. European Journal of Pediatrics, 176, 723-729. https://doi.org/10.1007/s00431-017-2905-0

[10] DeBaun, M.R. and Vichinsky, E. (2007) Hemoglobinopathies. In: Nelson Textbook of Pediatrics, Elsevier Saunders, Philadelphia, 2025-2038.

[11] République du Sénégal (2016) Agence Nationale de la Statistique et de la Démographie. Enquête démographique et de santé à indicateurs Multiples. EDSV-MICS: 2010-2011: Rapport préliminaire. ANSD, Dakar.

[12] Mohammed, A.O., Attalla, B., Bashir, F.M., Ahmed, F.E., El Hassan, A.M., Ibnauf, G., et al. (2006) Relationship of the Sickle Cell Gene to the Ethnic and Geographic Groups Populating the Sudan. Community Genet, 9, 113-120. https://doi.org/10.1159/000091489 
[13] Tshilolo, L., Kafando, E., Sawadogo, M., Cotton, F., Vertongen, F., Ferster, A., et al. (2008) Neonatal Screening and Clinical Care Programmes for Sickle Cell Disorders in Sub-Saharan Africa: Lessons from Pilot Studies. Public Health, 122, 933-941. https://doi.org/10.1016/j.puhe.2007.12.005

[14] Venturini, E., Turkova, E., Chiappini, E., Galli, L., De Martino, M. and Thorne, C. (2014) Tuberculosis and HIV Co-Infection in Children. BMC Infectious Diseases, 14, Article No. S5. https://doi.org/10.1186/1471-2334-14-S1-S5

[15] Boheme, C.C. (2011) Feasibility, Diagnostic Accuracy and Effectiveness of Decentralised Use of the Xpert MTB/RIF Test for Diagnostic of Tuberculosis and Multidrug Resistance: A Multicenter Implementation Study. Lancet, 377, 1495-1505.

[16] M'Pemba Loufoua Lemay, A.B., Mabiala Babela, J.R., Bantsimba, T. and Nzingoula, S. (2007) Tuberculosis and HIV/AIDS Co-Infection in Children: Experience Carried out in Paediatric Service of the Teaching Hospital of Brazzaville, Republic of Congo (1995-2004). Bulletin de la Société de Pathologie Exotique, 100, 51-52.

[17] Kouéta, F., Ouédraogo, G., Dao, L., et al. (2011) Tuberculose chez les enfants infectes par le VIH suivis au chu pédiatrique Charles De Gaulle de Ouagadougou (Burkina Faso). Mali Medical, 4, 44-49.

[18] De Montalembert, M. (1996) Stimulation de la production d'hémoglobine fotale chez l'enfant drépanocytaire. Archives de Pédiatrie, 3, 207-209. https://doi.org/10.1016/0929-693X(96)81165-1

[19] De Montalembert, M. and Bachir, D. (2003) Traitement de la drépanocytose par l'hydroxyurée. In: Girot, R., Bégué, P. and Galacféros, F., Eds., La drépanocytose, John Libbey, Paris, 255-266.

[20] Zar, H.J., Workman, L., Isaacs, W., Dheda, K., Widaad Zemanay, W. and Nicol, M.P. (2013) Rapid Diagnosis of Pulmonary Tuberculosis in African Children in a Primary Care Setting by Use of Xpert MTB/RIF on Respiratory Specimens: A Prospective Study. Lancet Global Health, 1, E97-E104. https://doi.org/10.1016/S2214-109X(13)70036-6

[21] Oberhelman, R.A., et al. (2015) A Controlled Study of Tuberculosis Diagnosis in HIV-Infected and Uninfected Children in Peru. PLoS ONE, 10, e0120915. https://doi.org/10.1371/journal.pone.0120915

[22] Starke, J.R. (2003) Pediatric Tuberculosis. Time for a New Approach. Tuberculosis, 83, 208-212. https://doi.org/10.1016/S1472-9792(02)00088-4

[23] Zar, H.J., Hanslo, D., Appoles, P., Swingler, G. and Hussey, G. (2005) Induced Septum versus Gastric Lavage for Microbiological Confirmation of Pulmonary Tuberculosis in Infants and Young Children: A Prospective Study. Lancet, 365, 130-134. https://doi.org/10.1016/S0140-6736(05)17702-2 